\title{
132. Preliminary Report on a New Cidarid Sea-urchin from the Western Pacific.
}

\author{
Hayato IKEDA. \\ Zoological Institute, Kyushu Imperial University, Fukuoka.
}

(Comm. by A. OKa, M.I.A., Nov. 12, 1935.)

In August, 1935, I stayed for a few days in Chichi-jima, the main island of the Bonin Group in the western Pacific, and had the opportunity of collecting sea-urchins. Among the collections there were some cidarids obtained at a station, about 100 fathoms in depth, between Chichi-jima and Haha-jima. One of these cidarids was a peculiar one in having quite unusual spines. A close examination done in laboratory revealed that this specimen is a very interesting and entirely unprecedented one, being adorned with imperforate primary tubercules which have naver been known to occur in recent forms. In this respect it has closer relations to some fossil forms than to any of the known recent ones as stated below and it may be undoubtedly new to science. Hence I give hereby a brief description of the species in the present paper; a detailed account on this unique animal will be left for the future. I would like, here, to express my hearty thanks to Professor Dr. Hiroshi Ohshima for his generosity rendered to me in forwarding the expedition to the island, and to Mr. Yusaku Machida who kindly helped me in many ways during my sojourn there.

\section{Psychocidaris gen. nov.}

Primary tubercules imperforate, non-crenulate. Pores non-conjugate, on the peristomial ambulacral plates they are diploporous. On the peristome only pluriseriate ambulacral plates are present; no plate interradially. Primary spines thick, thorny. Valve of large globiferous pedicellaria flask-shaped in profile.

Genotype: Psychocidaris ohshimai sp. nov.

Psychocidaris ohshimai sp. nov.

Spines and test dark yellow, secondary spines greenish. Test of moderate size, $38.5 \mathrm{~mm}$ in horizontal diameter, $23.5 \mathrm{~mm}$ in vertical diameter in the unique type. Apical system $17 \mathrm{~mm}$ wide, ca. $44 \%$ of h.d., compact and closely covered with small tubercules of uniform size. All oculars narrowly inserted. Madreporite scarcely larger than the other genital plates. Test thick, with a broad median interambulacral space, covered with small tubercules. Primary tubercules large, glassy, perfectly smooth, imperforate and non-crenulate. Areoles fairly large, distinctly sunken. Primary spines peculiar in shape: upper primaries acorn-shaped, ambital ones longer and somewhat flattened, all primaries but adoral club-shaped, adorned with very coarse, quite irregularly 
arranged thorns. Collar short, about $3 \mathrm{~mm}$ long. Ambulacra slightly sinuate, pores non-conjugate. Peristome as large as spical system. Peristomial ambulacral pores in double series. Valve of large globiferous pedicellaria flask-shaped in profile, distinctly distinguishable from those in any of the known resent cidarids.

Described from the unique specimen mentioned above, designated as the type and preserved in the collection of the Zoological Laboratory, Kyushu Imperial University.

It has long been believed that all cidarids have perforate primary tubercules, with the exception of some fossil genera as triassic Aplocidaris, cretaceous Tylocidaris or jurassic Merocidaris and Caenocidaris, all of which have imperforate tubercules. Although Psychocidaris, as diagnosed above, appears to have some resemblance to the fossil genus

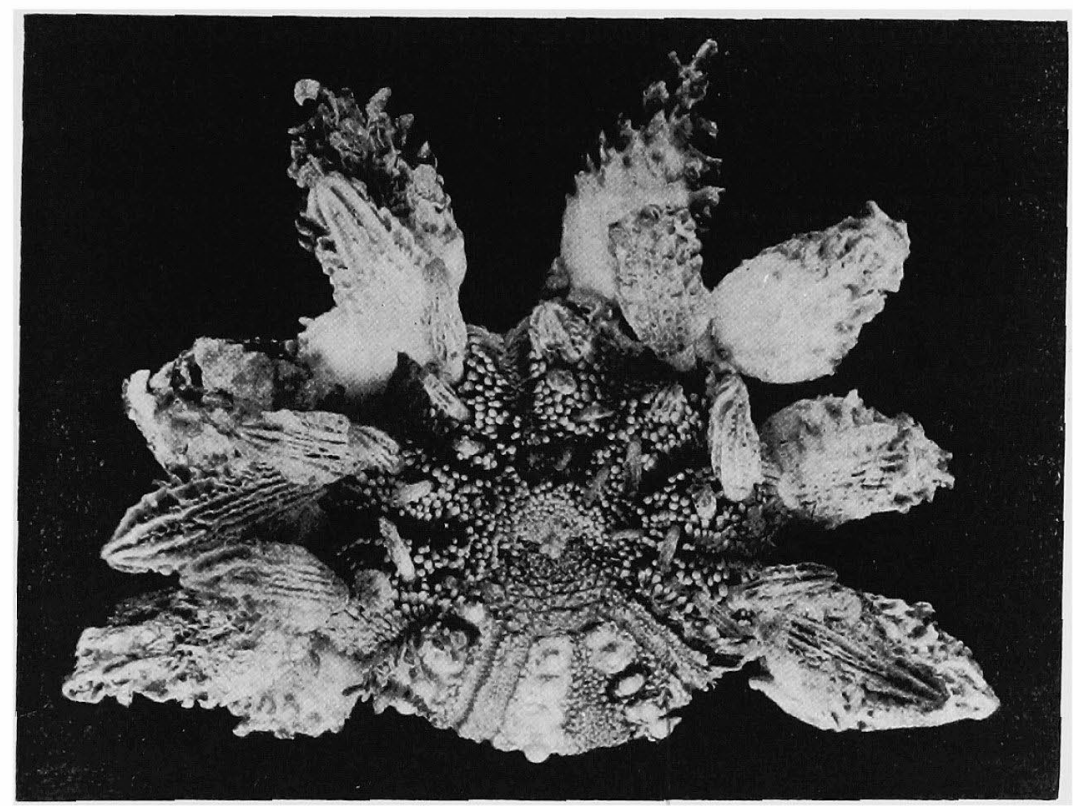

Oral side.

Psychocidaris ohshimai gen. et sp. nov.

(Natural size)

Tylocidaris, it may be fairly safe to assume that it is quite distinct from the latter, as there is a difference in the shape of the large globiferous pedicellaria seen in profile between the present from and Tylocidaris baltica (?), the figure of the latter was given by Mortensen (1). Mortensen found that the valve of the large globiferous pedicellaria is peculiar of the Cidaroidea, being originated from the fossil forms. The present species may represent another example of the case mentioned by Mortensen. The fact that only the pluriseriate ambulacral plates are found on the peristome is quite unusual, though very little classificatory value may attach to the arrangement of the peristomial interambulacral plates. So far as the peculiar peristome is concerned, the pluriseriate condition of the markedly specialized peristomial ambulacra of the jurassic genus Plegiocidaris may be reminded here. Döderlein (2) suggested that Plegiocidaris may be the direct ancestor of Tylocidaris 
based on the fact that the imperforate primary tubercules are on the adoral side. On the other hand, Mortensen (3) stated that Tylocidaris as well as Plegiocidaris left no descendants among recent cidarids. Although the phylogenetic relation between Psychocidaris and those fossil forms has not yet been sufficiently elucidated, it may be fairly justifiable to conclude that the recent form in question must be a descendant of one of them or their allies.

\section{Literature cited.}

1. Mortensen, Th. 1932. New contributions to the knowledge of the cidarids. I-II. Mem. Acad. Roy. Sci. Lett. Danemark, Copenhague, Sec. Sci., 9 ser. t. IV, no. 4, pp. 145-182.

2. Döderlein, L. 1887. Die Japanischen Seeigel. I. Theil. Familie und Saleniidae. pp. 1-59.

3. Mortensen, Th. 1928. A monograph of the Echinoidea. I. Cidaroidea. 